\title{
PENETAPAN KADAR FENOLIK TOTAL FRAKSI POLAR DAN NONPOLAR DAUN RAMBAI LAUT (Sonneratia caseolaris L.) DENGAN METODE SPEKTROFOTOMETRI UV-Vis
}

\author{
Siti Jubaidah ${ }^{1}$, Reksi Sundu ${ }^{2}$, Nur Sabriningsih ${ }^{3}$ \\ 1,2,3 Sekolah Tinggi Ilmu Kesehatan Samarinda \\ Email Korespondensi : $\underline{\text { ida_mapro13@yahoo.com }}$
}

\begin{abstract}
ABSTRAK
Rambai laut (Soneratia caseolaris L.) merupakan jenis pohon yang tumbuh di rawa-rawa tepi sungai atau hutan bakau yang mengandung salah satu metabolit sekunder berupa senyawa fenolik. Tujuan penelitian ini adalah mengetahui kadar fenolik total fraksi polar dan nonpolar daun rambai laut dengan metode spektrofotometri UV-Vis.

Penelitian yang dilakukan adalah noneksperimental. Tahapan penelitian meliputi determinasi tumbuhan, pengambilan sampel, pembuatan sampel, pembuatan ekstrak, penetapan kadar air ekstrak, fraksinasi menggunakan fraksi polar dan nonpolar, uji skrining fitokimia ekstrak etanol dan hasil fraksinasi dan penetapan kadar fenolik total dengan metode spektrofotometri UV-Vis.

Hasil penelitian menunjukkan bahwa fraksi polar daun rambai laut memiliki kadar fenolik total sebesar 213,49 \pm 1,2227 mg GAE/g yang artinya dalam setiap gram fraksi polar setara dengan 213,49 mg asam galat, sedangkan pada fraksi nonpolar daun rambai laut diperoleh sebesar 55,79 $\pm 1,0809 \mathrm{mg}$ GAE/g yang artinya dalam setiap gram fraksi nonpolar setara dengan $55,79 \mathrm{mg}$ asam galat. Kadar fenolik total lebih besar pada hasil fraksi polar.
\end{abstract}

Kata kunci: rambai laut, fenolik, spektrofotometri UV-Vis 


\section{ABSTRACT}

Rambai laut (Soneratia caseolaris L.) is a type of tree that grows in riverbank swamps or mangrove forests which contains one of the secondary metabolites in the form of phenolic compounds. The purpose of this study was to determine the total phenolic content of polar and nonpolar fractions of sea rambai leaves using UV-Vis spectrophotometry method.

Research conducted is non-experimental. The stages of the study included the determination of plants, sampling, making samples, making extracts, determining the water content of extracts, fractionation using polar and nonpolar fractions, phytochemical screening test of ethanol extract and fractionation results and determination of total phenolic levels by UV-Vis spectrophotometry.

The results showed that rambai laut leaf in polar fraction had a total phenolic content of $213.49 \pm 1.2227 \mathrm{mg}$ GAE / g, which means that in each gram the polar fraction is equivalent to $213.49 \mathrm{mg}$ of gallic acid, whereas in the nonpolar fraction of rambai laut leaves is obtained $55.79 \pm 1.0809 \mathrm{mg}$ GAE / $\mathrm{g}$ which means that in each gram the nonpolar fraction is equivalent to $55.79 \mathrm{mg}$ of gallic acid. Total phenolic content is greater in the polar fraction.

Keywords : rambai laut, phenolic, UV-Vis spectrophotometry

\section{PENDAHULUAN}

Rambai laut (Soneratia caseolaris L.) merupakan jenis pohon yang tumbuh di rawa-rawa tepi sungai atau hutan bakau. Rambai laut merupakan salah satu tumbuhan khas Kalimantan khususnya Kalimantan Selatan. Beberapa masyarakat menggunakan bagian daun rambai laut sebagai obat luka, obat cacar dan bedak dingin. Berdasarkan penelitian (Parnadi, 2017) menyatakan bahwa hasil skrining fitokimia daun rambai laut mengandung metabolit sekunder golongan fenol, flavonoid, saponin dan tanin.

Ribuan senyawa fenolik di alam telah diketahui strukturnya antara lain flavonoid, fenilpropanoid, fenol monosiklik sederhana, polifenol (melanin, lignin, tanin) dan kuinon fenolik (Tahir, dkk., 2017). Kemampuan senyawa fenolik memberikan peran besar sebagai senyawa biologik terhadap kepentingan manusia. Sejumlah senyawa fenolik mempunyai sifat medis dan telah digunakan sebagai obat seperti obat kanker (Sarker dan Nahar, 2007).

Cara yang digunakan untuk pemisahan senyawa adalah fraksinasi. Fraksinasi merupakan proses pemisahan senyawa berdasarkan tingkat kepolarannya (Rohman, 2009).

Cara yang dikenal untuk identifikasi dan analisis kuantitatif senyawa fenol (penetapan kadar) adalah spektrofotometri. 
Metode spektrofotometri merupakan metode analisis yang menggunakan sumber radiasi untuk menganalisis senyawa kimia dengan panjang gelombang ultraviolet 200-400 $\mathrm{nm}$ dan sinar tampak 400-750 nm. Spektrofotometri mudah dikerjakan, dapat menganalisis suatu zat dalam jumlah sedikit, kepekaan analisis tinggi dan sederhana (Harborne, 1987).

Berdasarkan latar belakang diatas perlu dilakukan penelitian tentang penetapan kadar fenolik total fraksi polar dan nonpolar daun rambai laut (Sonneratia caseolaris L.) dengan metode spektrofotometri UV-Vis.

\section{METODE PENELITIAN}

\section{a. Alat dan Bahan}

Alat yang digunakan pada penelitian ini adalah alat soklet, ayakan mesh 60 , blender, pipet tetes, oven, cawan porselin, mikropipet 100-1000 $\mu 1$, spektrofotometri UV-Vis, gelas ukur 10 $\mathrm{mL}$, labu ukur $10 \mathrm{~mL}$ dan $100 \mathrm{~mL}$, timbangan analitik, batang pengaduk, corong gelas, tabung reaksi dan beaker glass $250 \mathrm{~mL}$.

Bahan yang digunakan ekstrak daun tua rambai laut, etanol $70 \%$, reagen asam galat, reagen Folin-Ciocalteau, natrium karbonat, kalium iodida, bismut nitrat, iodium $\mathrm{P}$, asam nitrat $\mathrm{P}$, raksa (II) klorida, n-heksan, etil asetat, asam klorida $2 \mathrm{~N}$, asam klorida pekat, amil alkohol, besi (III) klorida 1\%, serbuk magnesium, aquadest, aluminium foil dan kertas saring.

\section{b. Pengambilan Sampel}

Daun rambai laut tua yang diambil dibagian bawah daun nomor 3 atau yang berada dibagian batang tumbuhan. Daun rambai laut yang diperoleh dari Jalan Sumber Mas Kelurahan Pulau Atas.

c. Pembuatan Simplisia

Daun rambai laut tua dikumpulkan dan disortasi basah, dicuci bersih dengan air bersih dan mengalir kemudian ditiriskan. Daun dikeringkan dengan cara diangin-anginkan. Daun rambai laut yang sudah kering ditimbang dan dilakukan penetapan susut pengeringan untuk mengetahui kandungan air yang menguap setelah dikeringkan. Simplisia kering yang diperoleh dihaluskan dengan blender dan diayak menggunakan ayakan mesh 60 .

\section{d. Pembuatan Ekstrak}

Dipasang alat soklet, ditimbang sampel masing-masing 100 gram dibungkus dengan kertas saring, diikat kedua ujung kertas saring dengan benang dan dimasukkan kedalam alat soklet. Ditambahkan pelarut etanol $70 \%$ sebanyak $750 \mathrm{ml}$ dibagi menjadi 2 bagian, $600 \mathrm{~mL}$ dimasukkan kedalam labu alas bulat dan $150 \mathrm{~mL}$ dimasukkan kedalam tabung soklet untuk membasahi sampel. Proses ekstrasi dilakukan dengan suhu $70^{\circ} \mathrm{C}$ sampai tetesan siklus menjadi jernih ( \pm 21-25 kali siklus). Ekstrak cair yang diperoleh diuapkan di atas penangas air hingga diperoleh ekstrak kental.

\section{e. Fraksinasi}

Ditimbang ekstrak etanol daun rambai laut sebanyak 5 gram, dilarutkan dengan $50 \mathrm{ml}$ etanol $70 \%$ dan $50 \mathrm{ml}$ aquadest, dimasukkan dalam corong pisah. Ditambahkan pelarut n-heksan $25 \mathrm{~mL}$ kemudian dipartisi, sesekali tutup corong 
pisah dibuka untuk memisahkan gas, diamkan sampai terbentuk pemisahan, dikeluarkan fraksi n-heksan simpan dalam wadah. Fraksinasi dengan pelarut n-heksan dilakukan tiga kali berturut-turut dengan volume 25, 25 dan 25 mL. Hasil fraksi n-heksan dikumpulkan. Sisa fraksi n-heksan dan sisa fraksi etanol-air atau residu dikumpulkan, dipekatkan diatas penangas air.

f. Skrining Fitokimia Ekstrak Etanol dan Hasil Fraksinasi

1) Senyawa fenolik

Diambil sampel sebanyak 1 gram larutkan dengan etanol $70 \%$, masukkan kedalam tabung reaksi, ditambahkan dengan pereaksi $\mathrm{FeCl}_{3}$ $1 \%$ sebanyak 3 tetes. Jika terjadi perubahan warna menjadi hijau biru menunjukan adanya senyawa polifenol.

2) Senyawa Tanin

Diambil sampel sebanyak 1 gram dan ditambahkan $10 \mathrm{~mL}$ aquadest masukkan dalam tabung reaksi, panaskan selama 3 menit kemudian dinginkan dan saring. Filtrat ditambahkan aquadest sampai tidak berwarna, tambahkan 1-2 tetes pereaksi besi (III) klorida 1\%. Jika terjadi perubahan warna menjadi warna hijau kehitaman menunjukkan adanya kandungan tanin.

3) Senyawa Saponin

Diambil sampel sebanyak 0,5 gram dan ditambahkan $10 \mathrm{~mL}$ aquadest masukkan dalam tabung reaksi, panaskan kemudian dinginkan dan saring. Dikocok selama 10 detik kemudian terbentuk buih dan tidak hilang setelah ditambahkan 1 tetes asam klorida $2 \mathrm{~N}$ menunjukkan adanya kandungan saponin.

4) Senyawa Alkaloid

Diambil sampel sebanyak 0,5 gram, ditambahkan $1 \mathrm{~mL}$ asam klorida $2 \mathrm{~N}$ dan $9 \mathrm{~mL}$ aquadest masukkan kedalam tabung reaksi, panaskan selama 2 menit kemudian dinginkan dan saring. Filtrat dibagi menjadi 3 bagian untuk percobaan berikut:

a) Pereaksi Bouchardat

Pembuatan pereaksi bouchardat dengan melarutkan iodium $\mathrm{P}$ sebanyak 2 gram dan kalium iodida sebanyak 4 gram dengan aquadest hingga $100 \mathrm{~mL}$.

Filtrat ditambahkan pereaksi bouchardat dalam tabung reaksi, jika terbentuk endapan coklat atau hitam menunjukkan adanya kandungan alkaloid.

b) Pereaksi Dragendorf

Pembuatan pereaksi dragendorf dengan melarutkan 8 gram bismut nitrat dalam $20 \mathrm{~mL}$ asam nitrat $\mathrm{P}$ dan 27,2 gram kalium iodida $\mathrm{P}$ dalam 50 $\mathrm{mL}$ aquadest. Campur kedua larutan dan diamkan sampai memisah sempurna. Ambil larutan jernih dan encerkan dengan aquadest hingga $100 \mathrm{~mL}$.

Filtrat ditambahkan pereaksi dragendorf dalam tabung reaksi, jika terbentuk endapan jingga atau merah coklat menunjukkan adanya kandungan alkaloid.

c) Pereaksi Mayer

Pembuatan pereaksi mayer dengan melarutkan 1,36 gram raksa (II) klorida $\mathrm{P}$ dalam $60 \mathrm{~mL}$ aquadest, 
tambahkan pada larutan 5 gram larutan kalium iodida $\mathrm{P}$ dalam 10 $\mathrm{mL}$ aquadest, encerkan dengan aquadest hingga $100 \mathrm{~mL}$.

Filtrat ditambahakan pereaksi mayer dalam tabung reaksi, jika terbentuk endapan putih atau kuning menunjukkan adanya kandungan alkaloid. Alkaloid dianggap positif jika dari ketiga pengujian diatas, minimal ada dua pengujian yang positif.

5) Senyawa Flavonoid

Diambil sampel sebanyak 1 gram dan ditambahkan $10 \mathrm{~mL}$ aquadest masukkan dalam tabung reaksi, panaskan selama 5 menit kemudian dinginkan dan saring. Filtrat diambil $5 \mathrm{~mL}$ ditambahkan 0,1 gram serbuk magnesium, $1 \mathrm{~mL}$ asam klorida pekat dan $2 \mathrm{~mL}$ amil alkohol kocok dan biarkan memisah, bila terbentuk warna merah, kuning atau jingga pada lapisan amil alkohol menunjukkan adanya kandungan flavonoid.

g. Penetapan Kadar Fenolik

1) Pembuatan Panjang Gelombang Serapan Maksimum ( $\lambda$ Maks)

Dipipet $0,3 \mathrm{~mL}$ larutan standar (30 ppm) masukkan kedalam tabung reaksi ditambah $1,5 \mathrm{~mL}$ reagen Folin-Ciocalteau (1:10) gojog, diamkan selama 3 menit kemudian ditambahkan larutan natrium karbonat 1,2 $\mathrm{mL}$ gojog sampai homogen, diamkan selama 60 menit pada suhu kamar. Diukur absorbansi panjang gelombang 500-850 nm dan tentukan $\lambda \max$ dengan nilai absorbansi tertinggi.
2) Pembuatan Kurva Baku Asam Galat dengan Reagen

Folin-Ciocalteau

Dipipet $0,3 \mathrm{~mL}$ larutan standar $(10,20,30,40$ dan 50 ppm) masukkan kedalam tabung reaksi ditambahkan 1,5 $\mathrm{mL}$ reagen Folin-Ciocalteau (1:10) gojog, diamkan selama 3 menit. Ditambahkan larutan natrium karbonat 7,5\% 1,2 mL gojog sampai homogen, diamkan selama 60 menit pada suhu kamar. Diukur absorbansi panjang gelombang 756,40 $\mathrm{nm}$ dan buat kurva kalibrasi hubungan absorbansi dengan asam galat.

\section{3) Penetapan Kadar Fenolik Total}

Ditimbang $10 \quad \mathrm{mg}$ sampel masukkan kedalam gelas beker, dilarutkan dengan etanol $70 \%$ : aquadest (1:1) sebanyak $10 \mathrm{~mL}$. Larutan ekstrak dipipet $0,3 \mathrm{~mL}$ ditambah reagen Folin-Ciocalteau 1,5 mL, gojog kemudian diamkan selama 3 menit. Ditambahkan larutan natrium karbonat 7,5\% 1,2 $\mathrm{mL}$, diamkan selama 60 menit pada suhu kamar. Diukur absorbansi larutan ekstrak dengan Spektrofotometer UV-Vis pada panjang gelombang maksimum (Alfian dan Susanti, 2012)

\section{HASIL DAN PEMBAHASAN}

Hasil ekstraksi daun rambai laut (Sonneratia caseolaris L.) ekstrak kental yang diperoleh sebanyak 27,25 gram dan hasil rendemen ekstrak etanol yang diperoleh sebesar $27,25 \%$.

Tabel 1. Berat dan Rendemen Hasil Fraksinasi 


\begin{tabular}{clcc}
\hline No & Fraksi & $\begin{array}{c}\text { Berat } \\
\text { (gram) }\end{array}$ & $\begin{array}{c}\text { Rendemen } \\
(\%)\end{array}$ \\
\hline 1. & $\begin{array}{l}\text { Nonpola } \\
\mathrm{r}\end{array}$ & 0,41 & 8,2 \\
2. & Polar & 4,2 & 84 \\
\hline
\end{tabular}

Data yang diperoleh dari hasil fraksinasi nonpolar sebanyak $0,41 \mathrm{~g}$ dengan hasil rendemen sebesar 8,2 \% dan fraksinasi polar sebanyak 4,2 $\mathrm{g}$ dengan hasil rendemen sebesar $84 \%$. Perbedaan hasil rendemen menentukan kualitas ekstrak, semakin tinggi hasil rendemen maka semakin banyak ekstrak yang dihasilkan dan semakin tinggi hasil rendemen maka semakin baik kualitas ekstrak (Depkes RI, 2000).

Ekstrak etanol, fraksi polar dan nonpolar kemudian dilakukan skrining fitokimia dan dilakukan uji kadar fenolik total dengan metode Spektrofotometri UV-vis.

Tabel 2. Hasil Skrining Fitokimia

\begin{tabular}{|c|c|c|c|}
\hline \multirow[b]{2}{*}{ Uji } & \multicolumn{3}{|c|}{ Hasil } \\
\hline & Ekstra & Fraks & Fraksi \\
\hline Senyawa & $\mathrm{k}$ & $\mathrm{i}$ & Nonpol \\
\hline & Etanol & Polar & ar \\
\hline Fenolik & $(+)$ & $(+)$ & $(+)$ \\
\hline Tanin & $(+)$ & $(+)$ & $(-)$ \\
\hline Saponin & $(+)$ & $(+)$ & $(+)$ \\
\hline Alkaloid & $(-)$ & $(-)$ & $(-)$ \\
\hline Flavonoid & $(+)$ & $(+)$ & $(+)$ \\
\hline
\end{tabular}

Keterangan:

(+) mengandung senyawa metabolit sekunder

(-) tidak mengandung senyawa metabolit sekunder

Hasil skrining menyatakan bahwa daun rambai laut mengandung senyawa fenolik pada fraksi polar dan nonpolar, kemudian masing-masing fraksi dilakukan penetapan kadar fenolik total dengan metode Spektrofotometri UV-Vis.

Penetapan kadar fenolik total dilakukan dengan menggunakan reagen Folin-Ciocalteau. Teknik pengerjaan yang lebih sederhana dan reagen Folin-Ciocateau digunakan karena senyawa fenolik dapat bereaksi dengan Folin terbentuk larutan yang dapat diukur absorbansinya (Tahir, dkk. 2017). Larutan standar atau pembanding yang digunakan adalah asam galat, yang merupakan salah satu fenolik alami dan stabil. Asam galat direaksikan dengan reagen Folin-Ciocalteau menghasilkan warna kuning yang menandakan bahwa mengandung fenolik, kemudian ditambahkan dengan larutan natrium karbonat sebagai pemberi suasana basa. Selama reaksi berlangsung, gugus hidroksil pada fenolik bereaksi dengan reagen Folin-Ciocalteau membentuk kompleks berwarna biru. Warna biru yang terbentuk akan semakin pekat, setara dengan konsentrasi ion fenolat yang terbentuk. Semakin besar konsentrasi senyawa fenolik maka semakin pekat warna yang dihasilkan (Tahir, dkk. 2017).

Kadar fenolik total ditentukan terlebih dahulu dengan melakukan penetapan panjang gelombang serapan maksimum larutan standar asam galat dari range 500-850 $\mathrm{nm}$ menggunakan spektrofotometri UV-Vis. Panjang gelombang serapan maksimum yang diperoleh yaitu 756,40 nm. Dilakukan penetapan kurva baku larutan standar asam galat dari konsentrasi 10, 20, 30, 40 
dan 50 ppm. Hasil penetapan kurva baku dan diperoleh persamaan garis linear yaitu $\mathrm{y}=0,01202 \mathrm{x}+0,0616$ dengan konsentrasi korelasi ( $\mathrm{r}$ ) = 0,99833.

Kurva baku dan persamaan garis linear diperoleh untuk menentukan kandungan fenolik pada masing-masing sampel yaitu fraksi polar dan nonpolar. Pengukuran kadar fenolik menggunakan spektrofotometri UV-Vis, kandungan fenolik pada ekstrak dinyatakan sebagai ekuivalen asam galat atau Gallic Acid Equivalen (GAE) yaitu jumah miligram asam galat dalam setiap gram ekstrak. Diperoleh kadar fenolik total pada fraksi polar sebesar 213,49 \pm 1,22 $\mathrm{mg} \mathrm{GAE} / \mathrm{g}$ yang artinya dalam setiap gram fraksi polar setara dengan $213,49 \mathrm{mg}$ asam galat, sedangkan pada fraksi nonpolar diperoleh sebesar 55,79 $\pm 1,08 \mathrm{mg}$ GAE/g yang artinya dalam setiap gram fraksi nonpolar setara dengan 55,79 $\mathrm{mg}$ asam galat. Hasil uji penetapan kadar fenolik total dapat dilihat pada tabel 3.Tabel 3. Hasil Uji Penetapan Kadar Fenolik Total

\begin{tabular}{cccc}
\hline No. & $\begin{array}{c}\text { Samp } \\
\text { el }\end{array}$ & $\begin{array}{c}\text { Kadar } \\
\text { Fenolik } \\
(\mathrm{mg} / \mathrm{g})\end{array}$ & $\begin{array}{c}\text { Rata-rata } \\
\text { dan nilai } \\
\text { SD }\end{array}$ \\
\hline
\end{tabular}

\section{Fraksi polar}

$\begin{array}{ccc}\text { Uji ke } & 212,3294 & 213,49 \mathrm{~m} \\ \text { I } & & \mathrm{g} / \mathrm{g} \pm 1,22 \\ \text { Uji ke } & 213,3777 & \\ \text { II } & \\ \text { Uji ke } & 214,7670 & \end{array}$

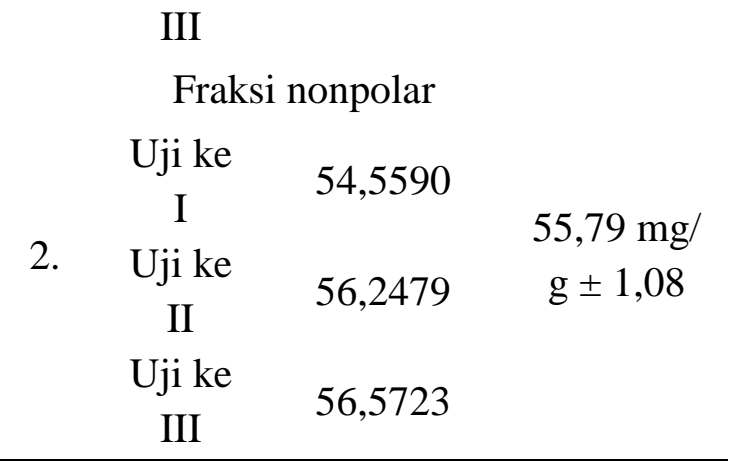

Nilai kadar fenolik total menunjukkan bahwa fraksi polar menghasilkan nilai kadar fenolik total yang lebih besar dibandingkan dengan fraksi nonpolar. Hal ini dikarenakan sebagian besar senyawa golongan fenolik dalam bentuk glikosid lebih mudah larut dalam pelarut polar seperti etanol, air dan metanol (Huoghton dan Raman, 1998). Senyawa fenolik berfungsi sebagai antikanker (Sarker dan Nahar, 2007).

\section{SIMPULAN}

Hasil penelitian yang telah dilakukan dapat disimpulkan bahwa fraksi polar memiliki kadar fenolik total lebih besar dibandingkan fraksi nonpolar. Kadar fenolik total fraksi polar sebesar 213,49 $\pm 1,22 \mathrm{mg}$ GAE/g, sedangkan pada fraksi nonpolar diperoleh sebesar $55,79 \pm 1,08 \mathrm{mg} \mathrm{GAE} / \mathrm{g}$.

\section{UCAPAN TERMIKASIH}

Penulis mengucapakan terimaksih kepada STIKES Samarinda yang telah mendukung dalam penelitian ini.

\section{DAFTAR PUSTAKA}

Alfian, R., dan Susanti, H. 2012. "Penetapan Kadar Fenolik Total 
Ekstrak Metanol Kelopak Bunga Rosella Merah (Hibiscus sabdariffa Linn) Dengan Variasi Tempat Tumbuh Secara Spektrofotometri”. Jurnal Ilmiah Kefarmasian. Yogyakarta: Universitas Ahmad Dahlan. Hal: 76. Diakses pada tanggal 5 Oktober 2018 dalam http://www.journal.uad.ac.id

Departemen Kesehatan RI. 2000. Parameter Standar Umum Ekstrak Tumbuhan Obat. Jakarta: Departemen Kesehatan RI. Hal: 1-2, 5, 10-11.

Harborne, J.B. 1987. Metode Fitokimia Penuntun Cara Modern Menganalisis Tumbuhan. Terbitan Kedua. Bandung: Penerbit ITB. Hal: 47, 49.

Huoghton,P.J., dan Raman, A. 1998. Laboratory Handbook for the Fractination of Natural Extracts. $1^{\text {st }}$ Ed. London: International Thomson Publishing. Hal: 15-16.
Parnadi, R.B. 2017. "Karakterisasi dan Skrining Fitokimia Simplisia Daun Rambai Laut (Sonneratia caseolaris L.)". Karya Tulis Ilmiah. Samarinda: Akademi Farmasi Samarinda. Hal: 31 .

Rohman, A. 2009. Kromatografi Untuk Analisis Obat. Yogyakarta: Graha Ilmu. Hal: 30-31.

Sarker, S.D., dan Nahar, L. 2007. Kimia Untuk Mahasiswa Farmasi Bahan Kimia Organik, Alam dan Umum. Yogyakarta: Pustaka Pelajar. Hal: 512-513.

Tahir, M., Muflihunna, A., Syafrianti. 2017. "Penentuan Kadar Fenolik Total Ekstrak Etanol Daun Nilam (Pogostemon cablin Benth.) dengan Metode Spektrofotometri UV-VIS". Jurnal Fitofarmaka Indonesia. Vol. 4 No. 1. : Universitas Muslim Indonesia. Hal: 215. diakses pada tanggal 10 Oktober 2018 dalam http://www.jurnal.farmasi.umi.ac.id 